\title{
Measurement of dose enhancement close to high atomic number media using optical fibre thermoluminescence dosimeters
}

\author{
Amani I. Alalawi ${ }^{\text {a,b,* }}$, R.P. Hugtenburg ${ }^{c}$, A.T. Abdul Rahman ${ }^{\text {d }}$, M.A. Barry ${ }^{\mathrm{e}}$, A. Nisbet $^{\mathrm{a}, \mathrm{e}}$, \\ Khalid S. Alzimami a,f , D.A. Bradley ${ }^{\mathrm{a}, \mathrm{g}}$ \\ a Department of Physics, University of Surrey, Guildford, Surrey, GU2 7XH, UK \\ ${ }^{\mathrm{b}}$ Physics Department, Umm AL-Qura University, Makkah, Kingdom of Saudi Arabia \\ ${ }^{\mathrm{c}}$ Department of Medical Physics and Clinical Engineering, Abertawe Bro Morgannwg UHB and School of Medicine, Swansea University, Swansea SA2 8PP, UK \\ ' School of Physics and Material Studies, UiTM, 72000 Kuala Pilah, Malaysia \\ e Department of Medical Physics, The Royal Surrey County Hospital NHS Trust, Guildford, GU2 7XX Surrey, UK \\ ${ }^{\mathrm{f}}$ Department of Radiological Sciences, King Saud University, Riyadh 11432, Kingdom of Saudi Arabia \\ ${ }^{\mathrm{g}}$ Department of Physics, University of Malaya, Campus of Negeri Sambilan, 72000 Kuala Pilah, Malaysia
}

\section{H I G H L I G H T S}

\author{
- Dose enhancement \\ - Thermoluminescence dosimeter \\ - Monte Carlo simulation
}

\section{A R T I C L E I N F O}

\section{Article history:}

Received 8 May 2013

Accepted 14 May 2013

Available online 29 May 2013

Keywords:

Dose enhancement

Thermoluminescence dosimeter

Monte Carlo simulation

\begin{abstract}
A B S T R A C T
Present interest concerns development of a system to measure photoelectron-enhanced dose close to a tissue interface using analogue gold-coated doped silica-fibre thermoluminescence detectors and an $\mathrm{X}$-ray set operating at $250 \mathrm{kVp}$. Study is made of the dose enhancement factor for various thicknesses of gold; measurements at a total gold thickness of $160 \mathrm{~nm}$ (accounting for incident and exiting photons) produces a mean measured dose enhancement factor of $1.33 \pm 0.01$ To verify results, simulations of the experimental setup have been performed.
\end{abstract}

(c) 2013 Elsevier Ltd. All rights reserved.

\section{Introduction}

A primary aim in radiotherapy is to maximise the treated volume dose while minimising dose to surrounding normal tissue. Present interest concerns tissue suitably loaded with a high atomic number medium, photon irradiation of this target promoting photoelectron production. Photoelectron generation approaches a maximum for incident photon energy $E$ just above the absorption edge, the photoelectric effect having an approximate $(Z / E)^{3}$ dependence with $Z$ the atomic number of the absorption material. The product photoelectrons and Auger electrons have relatively

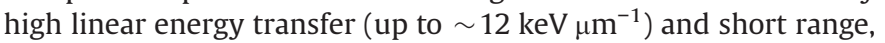
localising dose enhancement in the treated tissue, one such need being treatment of the thin (some tens of $\mu \mathrm{m}$ ) inflamed synovium of articulating joints in rheumatic arthritis. To ensure accurate

\footnotetext{
*Corresponding author. Tel.: +44 7825237060.

E-mail address: A.Alalawi@surrey.ac.uk (A.I. Alalawi).
}

measurement of dose, present research makes use of the TL signal stored in $\mathrm{Ge}$-doped $\mathrm{SiO}_{2}$ optical fibres, noting the TL response of doped silica optical fibres to be dependent on the presence of dopants, with non-uniformity in distribution of added dopants needing to be accounted for. The fibre dosimeters offer high spatial resolution, typically $\sim 100 \mu \mathrm{m}$, allowing use in a variety of interface dosimetry situations (Matsudaira et al., 1980; Spiers, 1949).

\section{Materials and methods}

The $\mathrm{SiO}_{2}-\mathrm{GeO}_{2}$ doped fibres (CorActive, Canada) used herein have a doped core and cladding diameter of $50 \mu \mathrm{m}$ and $124.7 \pm 0.1 \mu \mathrm{m}$ respectively. A fibre stripper (Miller, USA) is used to remove the outer coating, and for irradiation of the fibre is typically cut into lengths of $0.5 \pm 0.1 \mathrm{~cm}$. To mitigate against uncertainty in TL yield, the gross TL yield was normalised to unit mass of each irradiated fibre; the mean mass of a fibre was $(4.55 \pm 0.001) \mu \mathrm{g}$. Fibres selected by screening with a fixed dose 
provided a uniform response $(< \pm 4 \%$, i.e. $\sim 1$ S.D of the group mean); details have been provided elsewhere (Bradley et al., 2007). For coating, a set of fibres prepared in the same way were cut into $1 \mathrm{~cm}$ lengths to allow ease of handling, also being easily accommodated in the sputter coating machine.

Screened $\mathrm{SiO}_{2}-\mathrm{GeO}_{2}$ doped fibres were coated using a turbo sputter coater (Quorum Technologies Ltd, UK), producing 20, 40, 60,80 , and $100 \mathrm{~nm}$ thick coatings. Consistency was ensured using a $2 \mathrm{~V}$ motor located inside the sputterer (Fig. 1), providing 1540 revolutions $\mathrm{min}^{-1}$ during the coating process. The fibres were then cut into $0.5 \pm 0.1 \mathrm{~cm}$ lengths as above. Prior to read out, removing of the gold coating was carried out using a solution of $1 \mathrm{~g}$ iodine, $3 \mathrm{~g}$ potassium iodide, and $20 \mathrm{ml}$ of deionised water at room temperature. The procedure has no known deleterious effect upon the TL signal (Williams et al., 2003).

The fibres were irradiated in a specially designed Perspex cube phantom of side $6 \mathrm{~cm}$, with a series of six internal steps, each of which was $0.5 \mathrm{~cm}$ high and $1.0 \mathrm{~cm}$ wide. During irradiation, optical fibres were placed on each step of the phantom, 20 fibres being used at each step location, 10 of these being coated and placed in close proximity with each other and placed towards one end of

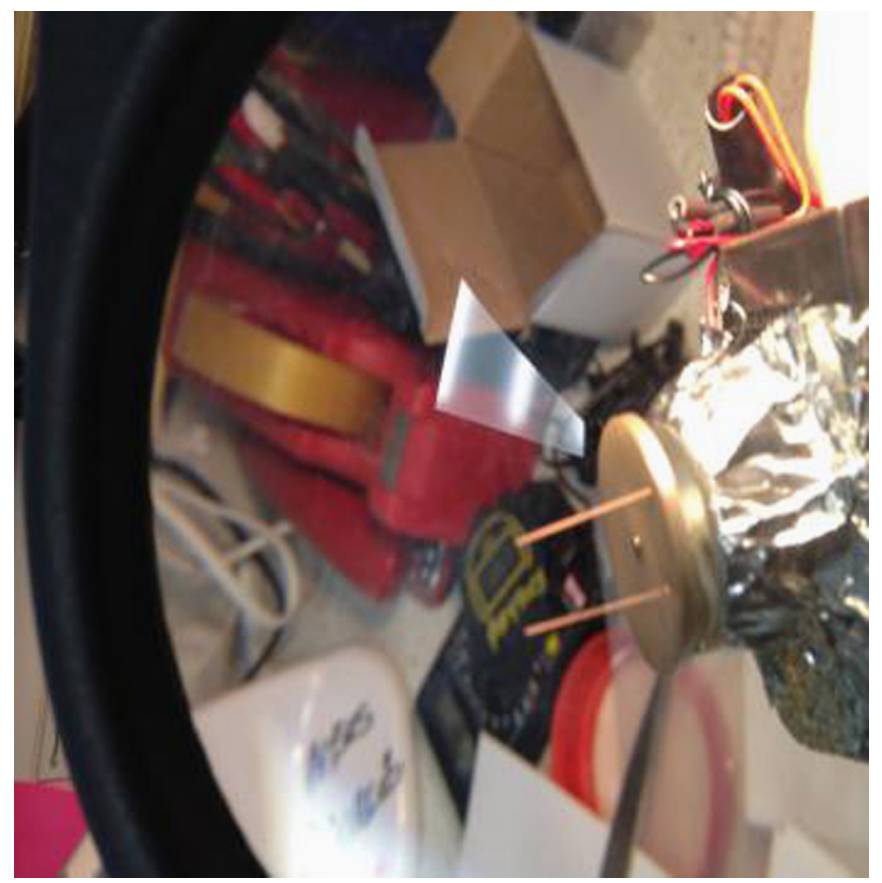

Fig. 1. Magnified view of coated fibres mounted on a $2 \mathrm{~V}$ electric motor. The view, taken through the magnifier, shows two coated fibres located on a platform attached to the electric motor. each step, each step being used for a different coating thickness of gold. For comparison, at each location 10 non-coated fibres were placed in close proximity with each other and located towards the other end of the step. Irradiation was carried out using an orthovoltage X-ray unit (GULMAY MEDICAL, Surrey UK), to deliver a dose of $3 \mathrm{~Gy}$. The unit has a $1 \mathrm{~mm}$ lead window, half value layer HVL $2.7 \mathrm{~mm} \mathrm{Cu}$, FSD $50 \mathrm{~cm}$, added filtration (in mm) $1.5 \mathrm{Al}+0.25 \mathrm{Cu}$ $+0.5 \mathrm{Sn}$. A tube current of $12 \mathrm{~mA}$ and tube potential of $250 \mathrm{kVp}$ was used.

To allow uniform control of thermal fading, optical fibre TL yield was measured 12 hours post-irradiation using a TOLEDO thermoluminescence dosimetry reader (Pitman Instruments, Weybridge, UK). The readout was carried out in the presence of $\mathrm{N}_{2}$ gas flow to suppress the effects of oxidation and triboluminescence. The parameters found to provide an optimal glow curve were: preheat temperature $160{ }^{\circ} \mathrm{C}$ for $10 \mathrm{~s}$; readout temperature $300{ }^{\circ} \mathrm{C}$ for $25 \mathrm{~s}$ at a ramp rate of $25{ }^{\circ} \mathrm{C} / \mathrm{sec}$. An annealing temperature of $300{ }^{\circ} \mathrm{C}$ for $10 \mathrm{~s}$ was subsequently used to eliminate any residual signal. In addition to experimental measurements, Monte Carlo simulation was carried out using the FLUKA code version 2011.2.2 (Ferrari et al., 2005; Battistoni et al., 2007) and the EGSnrc-based DOSRZnrc (Mainegra \& Kawrakow, 2012). The codes use an original transport algorithm for charged particles that can simulate the photoelectric effect with actual photoelectron angular distribution according to the fully relativistic theory of (Sauter, 1931).

The $250 \mathrm{kVp}$ spectrum incident on the phantom was generated using the programme SpekCalc (Poludniowski et al., 2009), also subsequently used in the Monte Carlo simulations to detect changes in the spectrum obtained at each step depth; Fig. 2. Details of the experimental set up have all been taken into account in the simulation, tracking $10^{7}$ and $10^{8}$ photon histories for FLUKA and DOSRZnrc respectively in a total CPU time of $3.6 \mathrm{~h}$. The phantom has been sampled as a cylinder rather than a cube in order to allow comparison with the DOSRZnrc simulation. Dose distributions in each gold thickness were scored by the USRBIN detector card with 21 bins. Energy cutoff was set to $1 \mathrm{keV}$ for photons and $10 \mathrm{keV}$ for electrons.

The dosimeter response in simulation was considered as energy deposited per unit mass. TL yields were also normalised to that resulting from a standard entrance dose to the surface.

\section{Results and discussion}

For a given location, the dose enhancement factor (DEF) is defined as the ratio of dose deposited in the Au-coated fibre, divided by the dose deposited in the uncoated fibre. The highest measured dose enhancement was $1.33 \pm 0.01$ for a $80 \mathrm{~nm} \mathrm{Au}$ coating thickness, corresponding to a maximum path length through which a photon can travel of $160 \mathrm{~nm}$; Fig. 3 and 4 .

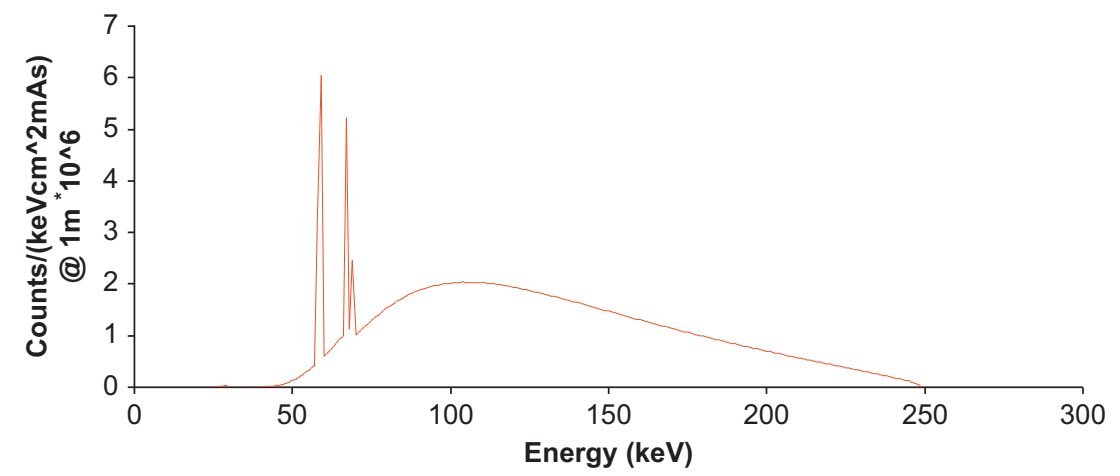

Fig. 2. $250 \mathrm{kVp}$ spectrum with SpekCalc programme. 


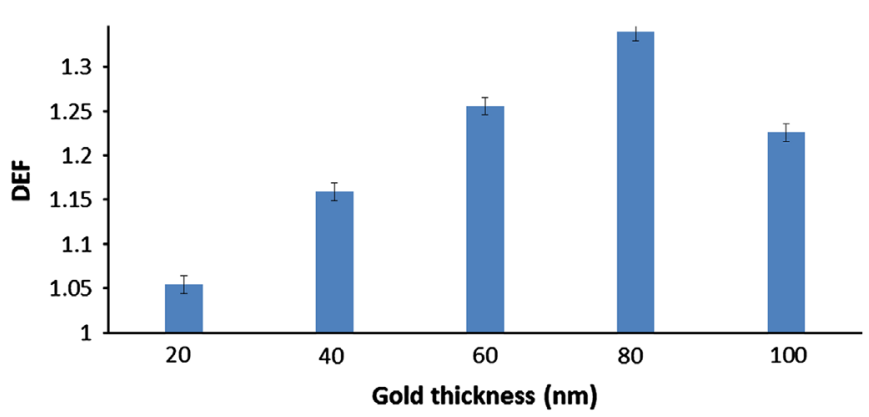

Fig. 3. DEF for different thickness of gold

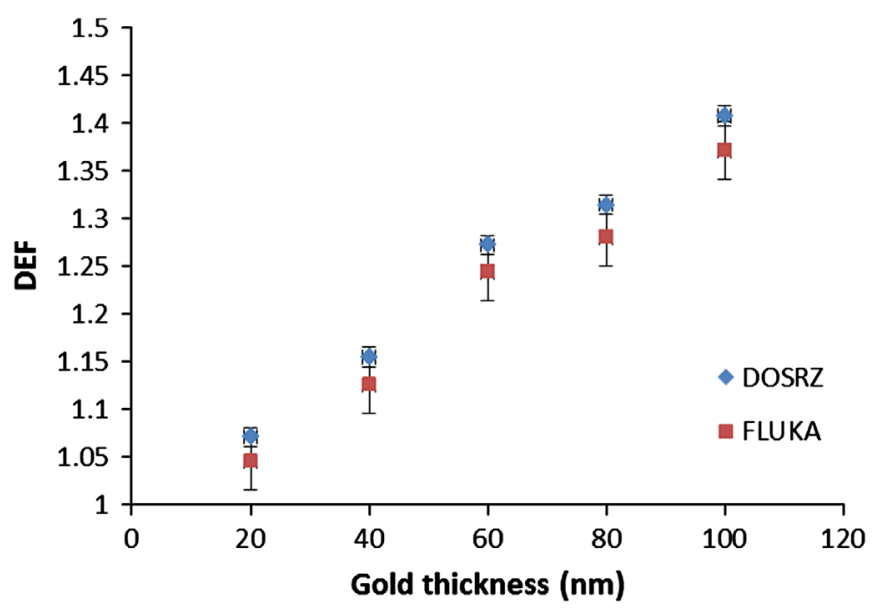

Fig. 4. DEF for different thicknesses of gold coating, simulated using FLUKA and DOSRZ

The reduction in DEF at $100 \mathrm{~nm}$ gold coating (200 $\mathrm{nm}$ maximum path length through which a photon can travel) has been shown to be due to incomplete removal of the Au-coating (as verified by optical microscopy). Both simulation codes show continuous increase in dose enhancement with gold thickness at the given dose, producing similar DEFs that differ in trend by $<3 \%$. The simulations and measured DEFs similarly agree with each other, indicating a DEF of $(0.016 \pm 0.001) \mathrm{nm}^{-1} \mathrm{Au}$.

\section{Conclusion}

In studies to-date, dose enhancement has been measured using Ge-doped fibres as a dosimeter, coated with different thicknesses of gold to generate photoelectrons. The experimental and simulation results are in agreement, producing a DEF of some $1.6 \% \mathrm{~nm}^{-1}$ of gold coating using presently reported conditions. A practical issue concerns use of chemicals to remove the gold, currently leading to incomplete removal of the thickest gold coating layer $(100 \mathrm{~nm})$. It is appreciated that more aggressive chemical treatments may damage the surface, reducing the TL yield. The dose enhancement technique offers potential for a number of thin target radiotherapy treatments, as in radiation synovectomy, overcoming issues in use of radioactive materials and in use of metallised nanoparticles. The analogue gold coated fibre TL measurement technique has been developed in association with Monte Carlo methods to verify the delivered dose in such thin targets. The technique avails itself to study of DEFs for other metallic element coatings.

\section{Acknowledgement}

The authors would like to thank Dr. Abdullah Khalil for his help in designing the gold coating setup and Mr. Maan Najem and Mr. Arron Shutt for their help regarding the FLUKA simulations.

\section{References}

Bradley, D.A., Hugtenburg, R.P., Hashim, S., Okoya, O.O., Yusoff, A.L., Hassan, A.A.M. Wagiran, H. (2007). The development of doped radiosensitive glass, AIP Conference Proceedings, 909(1), 9-18.

Battistoni, G.S.M., Sala, P.R., Cerutti, F., Ferrari, A., Roesler, S., Fasso, P.R., Ranft, J., (2007). The FLUKA code: description and benchmarking. Paper presented at the AIP Conference Proceeding.

Ferrari, A., Fasso, P.R. and Ranft, J.. (2005). FLUKA: a multi-particle transport code (Version 10): CERN.

Mainegra, E., \& Kawrakow, I. (2012). Graphical user interface for EGSnrc RZ user codes (Version 1.0). Canada: National Research Council Canada.

Matsudaira, H., Ueno, Akiko M., Furuno, Ikuko, 1980. Iodine contrast medium sensitizes cultured mammalian cells to X-rays but not to $\gamma$ Rays. Radiat. Res. 84 (1), 144-148, http://dx.doi.org/10.2307/3575225.

Poludniowski, G., Landry, G., DeBlois, F., Evans, P.M., Verhaegen, F., 2009. SpekCalc: a program to calculate photon spectra from tungsten anode X-ray tubes. Phys. Med. Biol. 54 (19), N433.

Sauter, F., 1931. Ueber den atomaren photoeffekt bei grosser haerte der anregenden strahlung. Ann. der Phys. 9, 217-247.

Spiers, F.W., 1949. The Influence of energy absorption and electron range on dosage in irradiated bone. Br. J Radiol. 22 (261), 521-533, http://dx.doi.org/10.1259/ 0007-1285-22-261-521.

Williams, K.R., Gupta, K., Wasilik, M., 2003. Etch rates for micromachining processing-Part II. J Microelectromech. Syst. 12 (6), 761-778. 